\title{
Breve história da hanseníase: sua expansão do mundo para as Américas, o Brasil e o Rio Grande do Sul e sua trajetória na saúde pública brasileira Trajectory in the Brazilian Public Health
}

Letícia Maria Eidt

Médica dermatologista, Especialista em Hansenologia pela Sociedade Brasileira de Hansenologia, Mestre em Educação pela PUCRS, Preceptora do Programa de Residências Integradas em Saúde da Escola de Saúde Pública da Secretaria Estadual de Saúde do Rio Grande do Sul. Ambulatório de Dermatologia Sanitária

E-mail: jose.arthuræbol.com.br

\section{Resumo}

Este trabalho faz uma revisão sobre a história da hanseníase através dos tempos, desde sua provável origem na Antigüidade até a sua vinda para as Américas, o Brasil e o Rio Grande do Sul. Relata, também, a evolução das políticas de saúde pública brasileiras adotadas para o seu controle e descreve algumas atitudes da sociedade para com os doentes de hanseníase no passado. Este retrospecto histórico contribui para o conhecimento da doença, para a detecção de fatores predisponentes do binômio saúde-doença e auxilia na compreensão dos sentimentos dos pacientes com relação a sua doença na atualidade.

Palavras-chave: Hanseníase; História; Saúde Pública; Políticas de Saúde.

\footnotetext{
Abstract

This work makes a review about the history of the Hansen's disease through the time, since its beginning until its arrival in Americas, in Brazil and in Rio Grande do Sul State. Reports the evolution of the public health policies for its control and describes some attitudes of the society with these patients in the past. This history helps to the knowledge of the disease, to the detection of the predisponent factors of the phenomenon health and disease and to understand the feelings of the patients about their disease in the present days.

Key Words: Hansen's Disease; History; Public Health; Health Policies.
} 


\section{Introdução}

A hanseníase, conhecida desde os tempos bíblicos como lepra (Bíblia Sagrada, 1992), é uma doença infecto-contagiosa de evolução crônica que se manifesta, principalmente, por lesões cutâneas com diminuição de sensibilidade térmica, dolorosa e tátil. Tais manifestações são resultantes da predileção do Mycobacterium leprae (M. leprae), agente causador da doença de Hansen, em acometer células cutâneas e nervosas periféricas. Foi o médico norueguês Gerhard Armauer Hansen, notável pesquisador sobre o tema, que identificou, em 1873, este bacilo como o causador da lepra, a qual teve seu nome trocado para hanseníase em homenagem ao seu descobridor (Foss, 1999 e Gomes, 200o). Durante as reações (surtos reacionais), vários órgãos podem ser acometidos, tais como, olhos, rins, supra-renais, testículos, fígado e baço (Talhari e Neves, 1997).

Se o M. leprae acometesse somente a pele, a hanseníase não teria a importância que tem em saúde pública. Em decorrência do acometimento do sistema nervoso periférico (terminações nervosas livres e troncos nervosos) surgem a perda de sensibilidade, as atrofias, paresias e paralisias musculares que, se não diagnosticadas e tratadas adequadamente, podem evoluir para incapacidades físicas permanentes (Brasil, 2001).

Esta doença representa, ainda hoje, um grave problema de saúde pública no Brasil. Além dos agravantes inerentes a qualquer doença de origem sócio-econômica, ressalta-se a repercussão psicológica ocasionada pelas seqüelas físicas da doença, contribuindo para a diminuição da auto-estima e para a auto-segregação do hanseniano (Eidt, 200o).

A taxa de prevalência no Brasil é bastante variável, oscilando entre 0,4 a 17 casos por 10.000 habitantes (Brasil, 2001). As Regiões Norte e Nordeste apresentam as mais altas taxas de prevalência, concentrando maior parte dos casos, e os Estados de Santa Catarina e Rio Grande do Sul já eliminaram a hanseníase como problema de saúde pública, segundo os critérios da Organização Mundial de Saúde (OPS/ OMS, 2001). Conforme dados da Secretaria Estadual da Saúde, no ano de 2002, o Rio Grande do Sul apresentou uma taxa de prevalência de o,22 (Camello, 2002).

A hanseníase tem tratamento e cura. Porém, se no momento do diagnóstico o paciente já apresentar al- guma deformidade física instalada, esta pode ficar como seqüela permanente no momento da alta. Este dado reforça a importância do diagnóstico precoce e do início imediato do tratamento adequado para a prevenção das incapacidades físicas que a evolução da doença pode causar.

A multidrogaterapia (poliquimioterapia ou PQT) torna inviável o $M$. leprae, porém não recupera nem reverte as deformidades físicas já instaladas. Concomitante ao tratamento farmacológico, medidas de avaliação e prevenção das incapacidades físicas e atividades de educação para a saúde, incluindo o autocuidado, devem ser desenvolvidas.

Com a introdução das sulfonas, na década de 1940, para o tratamento da hanseníase, o controle desta doença deixa de ser feito através do isolamento e da segregação do doente (Avelleira e Nery, 1998; Virmond, 1995). Destacamos que desde a década de 1950 não existe mais a norma de isolar, compulsoriamente, o doente de hanseníase em hospitais-colônias para seu tratamento e a terapêutica é realizada em nível ambulatorial, desde então (Velloso e Andrade, 2002). No passado, entretanto, o tratamento dispensado aos doentes de hanseníase era outro e sobre isto falaremos neste trabalho, em que será abordado um pouco da história da hanseníase desde a Antigüidade até os dias atuais, as políticas de saúde pública brasileiras adotadas para o seu controle ao longo dos tempos e as atitudes da sociedade para com o hanseniano no passado.

\section{Histórico da Hanseníase: do mundo para as Américas, o Brasil e o Rio Gran- de do Sul}

De acordo com Opromolla (1981, p.1), "é difícil afirmar, com certeza, a época do aparecimento de uma doença baseada em textos antigos, a não ser que haja uma descrição razoável da mesma com citações dos aspectos que lhe são mais característicos. Se não for assim, e se nos basearmos apenas em dados fragmentários e em suposições dos tradutores daqueles textos, o assunto se torna confuso e gera uma série de falsas interpretações".

E esse pensamento aplica-se à hanseníase, pois nem sempre encontramos, nos textos antigos, uma 
descrição clara e precisa de sua clínica, possibilitando algumas confusões a respeito de sua história e evolução, em diferentes regiões do mundo, ao longo dos tempos.

\section{Focos primitivos e expansão da hanseníase pelo mundo}

A hanseníase, amplamente conhecida pela designação de lepra, parece ser uma das mais antigas doenças que acomete o homem e acredita-se que seja originária da Ásia (Jopling e McDougall, 1991 e Brasil, 1989). Outros autores (Brasil, 1989) também apontam a África como berço desta doença. Ainda hoje, discute-se se a hanseníase é de origem asiática ou africana.

Conhecida há mais de três ou quatro mil anos na Índia, China e Japão, já existia no Egito quatro mil e trezentos anos antes de Cristo, segundo um papiro da época de Ramsés II (Serviço Nacional de Lepra, 1960). Há evidências objetivas da doença em esqueletos descobertos no Egito, datando do segundo século antes de Cristo (Brasil, 1989).

Conforme Opromolla (1981), no livro "Nei Ching Wen", cuja autoria é atribuída ao Imperador chinês Huang Tin, traduzido entre 2698-2598 a.C., aparece o termo li-feng para designar paralisia grave e descrever um estado patológico que provoca queda de sobrancelhas, nódulos, ulcerações, dormência, mudança de cor da pele e desabamento do nariz.

Outra possível referência, na literatura chinesa antiga, é encontrada no livro "Analects", datado de 600 a.C., época da dinastia Chou. Neste escrito há referências que um dos discípulos de Confúcio sofria de uma doença parecida com a hanseníase virchowiana, mas a descrição da mesma é imprecisa e restam dúvidas a respeito. Nesta época a doença era conhecida como lai ping e Ta Feng (Opromolla, 1981).

Skinsnes (1973) nos reporta que uma das mais autênticas descrições da hanseníase é encontrada no manuscrito chinês intitulado "Remédios secretos completos”, escrito por volta de 190 a.C., no qual encontra-se a descrição de uma doença que provocava a perda de sensibilidade e o aparecimento de manchas vermelhas que inchavam e depois se ulceravam, ocorrendo em seguida queda de sobrancelhas, cegueira, deformidade nos lábios, rouquidão, ulceração das plantas, desabamento de nariz e deslocamento de articulações. Ainda conforme este autor, há escritos da
China que descrevem os primeiros sintomas do lai ping como dormência da pele e sensação de vermes andando sob ela.

Conforme Opromolla (1981), na Índia, o "Sushruta Samhita”, datado de 600 a.C., descreve hiperestesia, anestesia, formigamento e deformidades sob os termos vat-ratka e vatsonita. Sob a designação de kushtha, cita três espécies de manifestações cutâneas principais: anestesia local, ulcerações e deformidades (queda dos dedos e desabamento do nariz).

Nos "Vedas" (140o a.C.) a hanseníase é mencionada como kushtha e, segundo Lowe (1947), alguns autores afirmam que nas "Leis de Manu" (1300-500 a.C.) há instruções sobre a profilaxia da hanseníase.

Para Opromolla (1981, p.2), "há referências de que a hanseníase existia em muitos outros lugares da Terra nesses tempos antigos, mas na verdade o que houve foram traduções errôneas de termos designando diferentes moléstias". Nos tempos Babilônicos, por exemplo, há referências sobre a hanseníase como a palavra lepra, mas seu significado era de uma doença escamosa. A palavra epqu, que foi traduzida como lepra no Dicionário Assírio, também significa escamoso. Ainda conforme este autor, a hanseníase existia em épocas remotas no Egito e era citada no "Papiro de Ebers" (130o-180o a.C.). Contudo, o que foi traduzido como lepra no referido documento era uma queixa de sintomas externos para o qual eram prescritos ungüentos. Na tradução grega de textos hebraicos, a palavra tsaraath foi traduzida como lepra (leprós = escama). A palavra lepra também foi usada pelos gregos para designar doenças escamosas do tipo psoríase e eles designavam a hanseníase como elefantíase (Opromolla, 1981).

Citações sobre a Doença de Hansen também são feitas na Bíblia Sagrada (1992), entretanto, estas são confusas. Encontra-se, nos capítulos 13 e 14 do Levítico, o termo hebreu tsaraath ou saraath para designar afecções impuras. Estes termos foram traduzidos como lepra em vários idiomas, sem que se possa afirmar com certeza o seu significado original. Em hebraico, significavam uma condição de pele dos indivíduos ou de suas roupas que necessitava purificação. Opromolla (1981) nos coloca que aqueles que apresentavam o tsaraath deveriam ser isolados até que os sinais desta condição desaparecessem. Ainda conforme a Bíblia, o tsaraath na pele dos judeus seriam manchas 
brancas deprimidas em que os pêlos também se tornavam brancos.

Segundo Opromolla (1981), admite-se que a hanseníase era desconhecida na Europa na época de Hipócrates (467 a.C.). Nos trabalhos do "Pai da Medicina" não há referências a qualquer condição que se assemelhasse àquela doença. Aceita-se que as tropas de Alexandre o Grande, quando retornaram à Europa depois da conquista do mundo então desconhecido, tenham trazido indivíduos contaminados com a doença nas campanhas da Índia (30o a.C.).

Por volta do ano 150 d.C a doença já era bem conhecida. na Grécia, quando se encontram referências à mesma feitas por Aretaeus e Galeno. O primeiro autor, no seu trabalho intitulado "Terapêutica de Afecções Crônicas”, designa a hanseníase como elephas ou elefantíase. Nesta mesma obra ele fala da semelhança da pele doente à pele do elefante, que é espessada. Foi ele quem introduziu o termo facies leonina para designar o aspecto da face do paciente infiltrada pela moléstia. Estes autores já conheciam, bem no começo da nossa era, a hanseníase virchowiana, mas não fazem referências a distúrbios de sensibilidade (Opromolla, 1981).

Segundo Jopling e McDougall (1991), da Grécia a Doença de Hansen foi lentamente disseminando-se para a Europa, carregada por soldados infectados (cruzados), comerciantes e colonizadores, sendo mais prevalente entre os séculos $\mathrm{X}$ e XV.

Acontece, porém, que a hanseníase era designada como lepra, como eram assim denominadas várias outras doenças de pele que se supunham ser idênticas ou ter alguma relação com ela.

O termo lepra absorveu, então, outras designações da doença como elefantíase. Daniellsen e Boeck (1848) dizem que a palavra lepra era usada para designar diferentes patologias cutâneas, uma vez que os médicos antigos não tinham uma idéia exata das doenças dermatológicas. Alguns colocavam na mesma categoria o líquen, a psoríase, a escabiose, o impetigo e a hanseníase.

Encontramos em Opromolla (1981) que o diagnóstico da doença era feito de uma maneira imprópria, o que pode ter contribuído, mais ainda, para confusões a cerca da doença hanseníase. A Lei de Strasbourg, no final do século XV, exigia que quatro pessoas fossem designadas para examinar um leproso: um médico, um cirurgião e dois barbeiros. Eles tinham que realizar os testes de urina e de sangue nos pacientes.

Conforme este autor, uma pequena amostra de sangue era depositada em um recipiente com sal. Se o sangue se descompusesse, o paciente era são, caso contrário, era considerado doente. Outra técnica consistia em misturar a água com o sangue. Se a mistura dos dois líquidos fosse impossível, tratava-se do sangue de um hanseniano. Quando se juntavam gotas de sangue ao vinagre, se não houvesse formação de bolhas, igualmente era firmado o diagnóstico de hanseníase. A análise de sangue tornou-se tão importante para o diagnóstico desta doença que um médico da Alsacia escreveu que o teste sangüíneo era absolutamente necessário para o seu diagnóstico. Convém ressaltar, aqui, que o diagnóstico de hanseníase é, predominantemente, feito pelo exame clínico e neurológico do doente.

Durante a Idade Média, segundo evidências de que se dispõe (Brasil, 1989), a hanseníase teve alta incidência na Europa e Oriente médio. De acordo com Pinto (1995, p.134), "os médicos medievais consideravam a lepra simultaneamente uma doença contagiosa e hereditária, ou oriunda de uma relação sexual consumada durante a menstruação".

O Concílio realizado em Lyon, no ano de 583, estabeleceu regras da Igreja Católica para a profilaxia da doença. Essas regras consistiam em isolar o doente da população sadia. Em algumas áreas, como a França, essas medidas de isolamento foram particularmente rigorosas e incluíam a realização de um ofício religioso em intenção do doente, semelhante ao ofício dos mortos, após o qual este era excluído da comunidade, passando a residir em locais especialmente reservados para esse fim. Era ainda obrigado a usar vestimentas características que o identificavam como doente e fazer soar uma sineta ou matraca para avisar os sadios de sua aproximação (Maurano, 1944).

De acordo com Opromolla (200o), nos anos 1100 houve um grande surto de simpatia e piedade pelos hansenianos, encorajado pela Igreja. A criação das primeiras ordens religiosas dedicadas a prestar cuidados a estes doentes datam dessa época. Essas ordens foram responsáveis pela criação de asilos para abrigar os acometidos pela doença. A Igreja ensinava que estas pessoas infelizes eram os pobres de Cristo. Muitas pessoas interpretavam e acreditavam que o 
próprio Cristo havia morrido com a Doença de Hansen e por isso damas nobres, em uma espécie de fervor religioso, lavavam os pés dos doentes e abraçavam seus corpos contaminados. Em muitos casos, estes devotos não corriam um risco maior do que o de adquirir a escabiose, em virtude das confusões diagnósticas já comentadas.

Como resultado desta "dedicação da comunidade" os lazaretos, destinados a abrigar os pacientes com hanseníase, foram fundados em todos os lugares. Mas, em virtude das confusões diagnósticas da época. nestes poderiam existir tanto os hansenianos, como os portadores de outras doenças cutâneas crônicas, pessoas sadias ou mendigos.

Pode-se estimar a magnitude da hanseníase na Europa no século XIII pela existência de quase 20.000 leprosários, ou lazaretos, naquele continente. Da mesma forma pode-se acompanhar o declínio da endemia européia, a partir do século XVII, pela desativação gradual dos mesmos asilos, que prosseguiu ao longo do século XVIII e primeira metade do século XIX (Maurano, 1944).

Por volta de 1870, a hanseníase já havia praticamente desaparecido em quase todos os países da Europa e, mesmo na Noruega, onde ainda podia ser considerada endêmica, sua incidência já se achava em declínio. Admite-se que este declínio teve como causa principal a melhoria das condições sócio-econômicas experimentadas pelos povos europeus ao longo das Idades Moderna e Contemporânea.

Ao mesmo tempo em que a hanseníase tendia ao desaparecimento na Europa, mantinham-se os focos endêmicos na Ásia e na África e introduzia-se a doença no Novo Mundo, a partir das conquistas espanholas e portuguesas e da importação de escravos africanos. Durante o período da colonização, a América Latina tornou-se, gradativamente, uma nova área endêmica mundial (Serviço Nacional de Lepra, 1960).

\section{A vinda da hanseníase para as Américas}

Nas Américas, a hanseníase deve ter chegado entre os séculos XVI e XVII com os colonizadores, pois não há evidências da existência da moléstia entre as tribos indígenas do Novo Mundo (Opromolla, 1981 e 200o).

Conforme dados do Serviço Nacional de Lepra (1960) e Opromolla (200o), nos Estados Unidos foram os franceses, fundadores do Estado de Louisiana, que trouxeram a doença. Na América do Sul ela veio, provavelmente, com os colonizadores espanhóis e portugueses, pois os primeiros doentes de hanseníase observados na Colômbia eram de origem espanhola. Ainda segundo dados do Serviço Nacional de Lepra (1960), alguns autores atribuíram ao Mal de Hansen as figuras de mutilações encontradas em vasos da época précolombiana.

Parece que o maior fator de expansão da hanseníase nas Américas foi o tráfico de escravos. Foram os negros que introduziram a doença na América do Norte pela Flórida, mas os chineses a difundiram na costa do Pacífico (Serviço Nacional de Lepra, 1960). De acordo com Johnston (1995), no Canadá os primeiros casos de hanseníase teriam sido detectados em 1815, entre imigrantes e trabalhadores chineses.

Na atualidade, todos os países sul-americanos têm hanseníase, sendo o Brasil o que apresenta as mais altas incidência e prevalência desta doença neste continente (OPS/OMS, 2001).

\section{A chegada da hanseníase no Brasil}

Assim como em outras regiões da América, não havia hanseníase entre os indígenas brasileiros. A doença entrou no Brasil, por vários pontos do litoral, com os primeiros colonizadores portugueses, principalmente açorianos, e para sua disseminação muito contribuíram os escravos africanos. Entretanto, outros povos europeus também colaboraram para sua disseminação posteriormente (Monteiro, 1987; Terra, 1926). Para Opromolla (2000), o papel desempenhado pelos escravos na introdução da hanseníase no Brasil é discutível, pois era difícil a negociação de africanos que apresentassem lesões cutâneas.

No Brasil, os primeiros casos da doença foram notificados no ano de 16oo, na cidade do Rio de Janeiro (Yamanouchi et al, 1993), onde, anos mais tarde, seria criado o primeiro lazareto, local destinado a abrigar os doentes de Lázaro, lazarentos ou leprosos (Brasil, 1989).

Opromolla (1981 e 200o) nos diz que os primeiros documentos que atestam a existência da hanseníase no território brasileiro datam dos primeiros anos do século XVII, tanto que em 1696 o governador Artur de Sá e Menezes procurava dar assistência, no Rio de Janeiro, aos doentes já então em número apreciável.

Após os primeiros casos no Rio de Janeiro, outros focos da doença foram identificados, principalmente 
na Bahia e no Pará (Yamanouchi et al, 1993). Tal fato, conforme Ministério da Saúde (Brasil, 1989), levou as autoridades da época a solicitarem providências a Portugal, sem, entretanto, serem atendidas.

Ainda segundo dados deste mesmo autor, as primeiras iniciativas do governo colonial só foram tomadas dois séculos depois do pedido das autoridades locais, com a regulamentação do combate à doença por ordem de D. João VI. Entretanto, as ações de controle se limitaram à construção de asilos e à assistência precária aos doentes.

Encontramos em Opromolla (1981) que são dois os documentos mais antigos, referentes à hanseníase no Estado de São Paulo. Um é a carta enviada ao Conde de Oyeiras, em 1765, onde o governador se refere ao perigo que corria a capitania em decorrência da doença. O outro documento são coletâneas das atas da cidade de São Paulo (1768) sobre o despejo de uma cigana doente a mando da vereança da cidade.

O primeiro censo em São Paulo sobre o número de casos de hanseníase foi em 1822, executado pelo Visconde de Oeynhausen, cujos dados não são conhecidos integralmente. 0 segundo censo foi realizado em 1851. Outros censos foram realizados depois, notando-se sempre um aumento do número de pacientes, o que acompanhava a marcha do progresso do Estado (Oprpmolla, 1981 e 200o).

Em decorrência do desenvolvimento da agricultura, novas terras foram sendo colonizadas e surgiu a necessidade de mão-de-obra. Como conseqüência houve a migração de vários doentes às mais diferentes regiões do território brasileiro. Estes focos, muito distantes um dos outros, correspondiam às cidades mais importantes política ou economicamente (Calmon, 1940). Pernambuco era o mais importante centro açucareiro do mundo, a Bahia, capital da Colônia e o Rio de Janeiro progredia tanto que se tornou a sede do Governo posteriormente. São Paulo iniciava o desenvolvimento de sua agricultura, abandonando o espírito aventureiro que provocara a conquista de Minas Gerais, Goiás e todo o Sul do País.

De acordo com Maurano (1944), após a introdução da moléstia por diversos pontos da costa brasileira, correspondentes aos principais centros da Colônia, a infecção teria acompanhado a marcha da colonização. De Pernambuco, um dos mais antigos centros da agricultura usineira, teria a moléstia se estendido à Paraí- ba e a Alagoas, devido ao desenvolvimento agrícola dessas regiões. E ao Ceará, Maranhão, Pará e Amazonas pela ocupação desses Estados.

De São Paulo, a infecção teria acompanhado os bandeirantes para Minas Gerais, Mato Grosso e Goiás. E seria de São Paulo, também, o foco da hanseníase para os Estados do Sul (Magalhães, 1882).

O Amazonas deve ter recebido a hanseníase do Pará, onde era grande a prevalência nos princípios do século XIX. As relações com Belém, Santarém e Manaus eram intensas nessa época por causa do desenvolvimento do comércio (Araújo, 1933). Esse mesmo autor afirma que "os nordestinos que iam à Amazônia voltavam, freqüentemente, leprosos" (p.165). Segundo Matta (1924, p.181), "o primeiro leproso registrado em Manaus data de 24 de fevereiro de 19o8."

A respeito ao papel do escravo africano na difusão da doença pelo nosso País, as opiniões dos autores divergem sobre o assunto. Maurano (1944) reporta que os escravos africanos não teriam introduzido a doença, mas contribuído para a sua disseminação. Na época Colonial, os critérios adotados para a entrada do escravo em nosso País eram muito rígidos, pois nenhum proprietário arriscaria comprar um serviçal com lesões de pele que pusessem em risco sua família e seus outros escravos. Monteiro (1987) nos lembra que a doença existia na África, portanto existe a hipótese no tráfico negreiro ter contribuído para o crescimento da hanseníase no Brasil, pensamento este também compartilhado por Souza Araújo (1946).

Maurano (1939), analisando a variação da freqüência da hanseníase desde os tempos coloniais até sua época, diz que a moléstia foi muito intensa no período colonial da metade do século XVIII até início do século XIX. A seguir, até os meados deste mesmo século, ela diminuiu de intensidade, tornando a se expandir com maior importância a partir de então, como conseqüência das correntes migratórias.

\section{A hanseníase no Rio Grande do Sul}

De acordo com Cunha (1997), as primeiras estatísticas sobre hanseníase, no Rio Grande do Sul, datam de 1905, porém, eram baseadas em informações indiretas e não oficiais e o foco mais antigo de hanseníase talvez tenha sido a cidade de Vacaria, onde a doença parece ter chegado difundida por paulistas no século XVIII. Quanto aos primeiros registros neste Estado, 
são importantes os relatórios de Souza Araújo (1918), que havia sido enviado pelo governo da República para avaliar a real situação da doença no País.

Conforme Maurano (1944), a Doença de Hansen disseminou-se em nosso País tanto pelas correntes migratórias internas, quanto pelas fronteiras de países limítrofes. Esta idéia é corroborada por Velloso e Andrade (2002), que referem ser o contato constante com habitantes de países limítrofes com o Rio Grande do Sul - Argentina, Paraguai e Uruguai - atingidos pela doença, um dos fatores de propagação da doença no Estado.

Pensamento semelhante tem Bassewitz (1927) a respeito da chegada e disseminação da hanseníase no Rio Grande do Sul. Nosso Estado deve ter recebido, além do contágio brasileiro, doentes provenientes dos países cisplatinos, dado o contato ininterrupto com os habitantes desses países.

Conforme o Serviço Nacional de Lepra (1960), no Sul do País foram encontrados casos de hanseníase provenientes de Portugal, Espanha, França, Rússia e países Balcânicos. De acordo com Cunha (1997), a participação de imigrantes alemães e italianos, com novos focos de hanseníase ao Rio Grande do Sul, não é unânime entre os autores. Estes imigrantes tanto poderiam ter sido infectados em seus países de origem, quanto nos navios que os transportaram para o Brasil. Como o período de incubação da doença é longo, os primeiros casos só teriam aparecido anos após a chegada dos imigrantes em solo gaúcho.

De início, a Doença de Hansen parece ter sido rara no Rio Grande do Sul. Sobre sua raridade nos escreve Magalhães (1882). Nessa época conheciam-se apenas casos isolados, pertencentes a membros de uma mesma família.

A partir de 1915, conforme Maurano (1944), começou o incremento da moléstia em nosso Estado. Segundo Faillace (1933), na década de 30, dois terços dos municípios do Rio Grande do Sul tinham casos registrados de hanseníase.

A partir de 1926, Borges de Medeiros começou a divulgar a idéia da construção de um hospital para abrigar os doentes com hanseníase, sendo que em 1936 foi fundado um hospital provisório em Porto Alegre e em 1940 foi inaugurado o Hospital Colônia Itapuã pelo Presidente Getúlio Vargas, localizado na cidade de Viamão, cerca de 6o Km de distância da ca- pital gaúcha (Cunha, 1997; Jornal do MORHAN, 200o).

Em 1939, dos 86 municípios gaúchos, existiam doentes em 45 deles, num total de 450 doentes. Embora a incidência não fosse uniforme, encontrava-se a doença no centro e nos quatro pontos cardinais do Estado (Maurano, 1944).

Maurano (1944, p.6o) nos diz que "não obstante se encontrar a lepra na maioria dos municípios da Encosta da Serra (região dos municípios para onde afluíram os imigrantes), era nos municípios das fronteiras com Argentina (Missões) e com Santa Catarina (Planalto Médio e do Nordeste) que se encontrava a maior incidência da lepra".

\section{Hanseníase e Sociedade: sobre as re- gras sociais impostas aos hansenia- nos no passado}

A hanseníase, na sua marcha invasora pelo organismo, acarreta alterações e deformidades físicas, se não tratada precocemente. Contudo, a vitalidade orgânica e a consciência do doente não se alteram. O hanseniano sofre mais moral do que fisicamente.

Esta moléstia, interpretada até mesmo como castigo divino, representa, desde os mais remotos tempos até os dias atuais, verdadeiro estigma social. É considerada mais do que uma doença. Por vezes representa uma humilhação extrema e uma condenação por um mal que o doente não cometeu (Eidt, 200o).

Da crença de sua contagiosidade e de sua incurabilidade nasceu o medo de contraí-la e sofrer todos os males que ela representa, dentre os quais o de ficar estigmatizado. Daí a repulsa que ela causava e o rigor social imposto aos seus portadores no passado.

Carvalho (1932) nos fala sobre as regras sociais impostas aos hansenianos antigamente. Os doentes deveriam andar com a cabeça coberta e com calçados para não infectarem os caminhos por onde passassem. Conforme Maurano (1944), eram obrigados a usar uma indumentária especial. Sobre o corpo deveriam usar uma túnica ou hábito cor parda, castanha ou negra e, em alguns países, deveriam ter sinais expostos sob a forma de mão ou "L". Deveriam avisar de sua passagem por meio de campainhas ou de matracas.

Em São Paulo, no ano de 1836, existiam leis que proibiam a parada de doentes, vindos de outros luga- 
res, nesta cidade, sob pena de expulsão e internação hospitalar. Várias leis paulistas os impediam de mendigar na cidade ou determinavam dias para este fim (Maurano, 1939). Conforme este autor, os hansenianos mendigavam tanto nas cidades, em pontos de maior movimento, como portas de igrejas, cemitérios e mercados, quanto das estradas.

Era-lhes proibido lavar as roupas em lugares públicos de uso comum, assim como só podiam passar à beira das estradas, sem entrar nas cidades. Sofriam castigos se entrassem nos moinhos e padarias ou se tocassem em alimentos expostos. Quando pretendiam comprá-los nos mercados, deveriam apontá-los e tocálos com uma vara longa de que andavam munidos.

Não podiam exercer qualquer profissão em que fosse necessário o manuseio de alimentos, roupas e outros objetos que seriam usados por pessoas sadias. Era-lhes proibida, especialmente, a profissão de açougueiros. A lei mais antiga que conhecemos, referente à proibição do exercício de certas profissões por hansenianos, data de 1848, na Província de Minas Gerais (Veiga, 1897).

Os doentes de hanseníase também eram proibidos de comerem ou dormirem com pessoas sadias. Durante algum tempo não lhes era permitido casarem-se com cônjuges que não fossem também doentes.

Após a morte dos hansenianos, as suas casas, móveis e roupas eram queimados e seus filhos, se fossem sadios, ficavam em lugares cuidados pela comunidade local. Em muitos países, embora isto não tenha sido observado no Brasil, os doentes eram considerados mortos civilmente e não podiam pleitear justiça, contratar serviços, vender produtos e nem deixar herdeiros (Maurano, 1944).

Carvalho (1932, p.10) nos diz que "os filhos dos leprosos não podiam ser batizados como as outras crianças pelo risco de poluírem as águas da pia batismal. A criança era afastada de maneira que a água lançada não caísse sobre a pia". Este autor ainda comenta que os doentes não podiam ser enterrados nos cemitérios comuns e muito menos entrar nas igrejas ou em contato com as pessoas sadias.

No Brasil, entretanto, não foi observado todo este rigor de uma maneira uniforme. A não ser o isolamento natural pela repulsão que eles provocavam, não houve entre nós regras sistemáticas contra os hansenianos. Pelo contrário, a tendência era olhá-los com piedade. Os administradores públicos, alvo algumas exceções, que adotaram medidas austeras e policiais, se portavam com certa brandura, inclusive convocando a população a adotar esta postura. Em São Paulo, por exemplo, existia o bom senso de poupar do isolamento aqueles doentes que tivessem família, a fim de não sofrerem a violência de serem arrancados de seu ambiente familiar e serem privados do convívio das pessoas que lhes eram mais importantes (Maurano, 1939).

Todos estes fatos, aqui citados, não passavam de atos esporádicos, realizados localmente, pois não existia nenhuma lei para aplicação sistemática em todo o Brasil. Os próprios hospitais de Lázaros de Rio de Janeiro (Pinheiro, 1894) e da Bahia (Guedes, 1930) em que se notava muito rigor, verifica-se que a preocupação maior era com a profilaxia.

\section{Crenças, Costumes e "Tratamentos" entre os Doentes de Hanseníase no Passado: à procura da cura}

No Brasil, assim como em outros países no mundo, a hanseníase é doença presente nas crenças e na cultura popular.

Segundo Maurano (1944), os leigos atribuíam como causa da hanseníase a ingestão de certos alimentos, a partir de observações naqueles lugares em que a doença existia de forma endêmica. Assim, incriminava-se a carne de porco e o pinhão em Minas Gerais e o peixe, o mel e algumas frutas em outras localidades. Entre outros, entretanto, havia a crença de que o bulbo do inhame, o caju e certas ervas medicinais a curassem.

Sobre as águas minerais, Veiga (1897) nos conta que há referências sobre as águas de Mariana (Minas Gerais) e Caldas Novas (Goiás) como fonte de cura para aqueles que sofressem de hanseníase.

Uma lenda existente em nosso País refere-se à crença que, se a doença fosse transmitida a sete pessoas, o seu portador seria curado. Há relatos de um episódio, em São Paulo, em que os hansenianos invadiram uma cidade ao norte deste Estado, procurando passar o mal à população. Esta teria reagido com armas de fogo e os doentes morrido ou fugido. Na fuga teriam encontrado uma criança na estrada e avança- 
do sobre ela às dentadas até ela sangrar, a fim de garantir a transmissão da doença. Conta-se também que muitos doentes fingiam-se de mortos nas estradas, esperando que os viajantes descessem de suas montarias para ajudá-los e os outros doentes, escondidos no mato, avançariam para passar-lhes o mal. Ainda desta crença, as mulheres doentes recorriam à prostituição para conseguirem sua cura (Maurano, 1944).

Outra lenda existente, segundo Maurano (1939), é a de que os doentes de hanseníase que proferissem pragas eficazes teriam sua moléstia transmitida a outras pessoas e a sua cura garantida.

Sobre formas de tratamento surgidas a partir destas crenças, Carvalho (1932) comenta sobre o emprego de ervas medicinais sobre as lesões cutâneas, cauterizadas com banhos à vapor, associadas a dietas especiais, laxantes e remédios eméticos.Maurano (1939) descreve a técnica de desidratar e debilitar o paciente, o que levava tão somente à redução do tamanho das lesões. Este autor refere, ainda, a técnica do banho de contraste (de um banho muito quente o doente passava, de imediato, para uma banheira de água gelada) e o emprego da saliva de pessoas jovens e sadias para transformar a hanseníase em alergia.

\section{As Políticas de Saúde Brasileiras para - Controle da Hanseníase através dos}

\section{tempos}

Segundo dados do Serviço Nacional de Lepra (1960), as medidas legislativas mais importantes até o século XX, ditadas para o controle da hanseníase no território nacional, foram: Lei tornando obrigatório o isolamento dos doentes de hanseníase no Rio de Janeiro, decretada em 1756; o regulamento assinado em 1787 por D. Rodrigo de Menezes para o hospital da Bahia; o isolamento obrigatório dos doentes no Estado do Pará em 1838; proibição do exercício de certas profissões pelos hansenianos em 1848 e de 1883 expedição de legislação apropriada com a criação de hospitais-colônias em Sabará.

Conforme Maurano (1939), a endemia hansênica evoluía há, aproximadamente, três séculos no Brasil e pouco ou quase nada havia sido feito para conter sua expansão. Foi Emílio Ribas que, no ano de 1912, durante o I Congresso Sul Americano de Dermatologia e Sifi- ligrafia do Rio, destacou a importância da notificação compulsória e de se tratar a hanseníase com rigor científico, além do "isolamento humanitário" em hospitais-colônias que não apenas abrigassem os doentes, mas, também, trabalhassem a questão da profilaxia, entre elas, afastar os filhos recém-nascidos sadios de seus pais doentes e dar-lhes assistência nos educandários ou preventórios. Este sanitarista aconselhava a ação conjunta do Estado, dos Municípios e da comunidade para resolver a questão da hanseníase em território brasileiro. Nesta época destaca-se o envolvimento de Oswaldo Cruz, no Rio de Janeiro, e de Alfredo da Matta, no Amazonas.

Por volta de 1916, era instituída, na cidade do Rio de Janeiro, a Comissão de Profilaxia da Lepra, da qual fazia parte Adolfo Lutz. Neste mesmo ano, Carlos Chagas presidiu o $1^{\circ}$. Congresso Americano de Lepra também nesta cidade (Velloso e Andrade, 2002).

O período compreendido entre 1912 e 1920 se constitui numa fase intermediária da história da hanseníase no Brasil, com o reconhecimento do problema pelas autoridades sanitárias. Emílio Ribas, Oswaldo Cruz e Alfredo da Matta começaram a denunciar o descaso do combate à endemia e a tomar medidas isoladas em suas áreas de atuação, merecendo destaque a iniciativa de Emílio Ribas em São Paulo (Brasil, 1989). Conforme Velloso e Andrade (2002, p.17), "as disposições do controle da lepra em vigor na época eram o recenseamento, a notificação obrigatória do paciente e daqueles com os quais convivia, a juízo da Saúde Pública, o isolamento obrigatório no domicílio, se a sua permanência no lar não constituísse risco aos demais, e a assistência pecuniária a esses doentes. Na dependência das condições sociais do caso, o isolamento dava-se em colônias agrícolas, sanatórios ou hospitais com ampla assistência médica e social, vigilância sanitária (exames clínico e bacteriológico) dos doentes em domicílio e das pessoas que os cercavam, vigilância dos casos suspeitos, proibição de mudar de residência sem prévia autorização das autoridades sanitárias, interdição do aleitamento materno aos filhos de leprosos e afastamento imediato dos mesmos para preventórios especiais, além da interdição da entrada de estrangeiros com lepra".

Em 1920, com a criação do Departamento Nacional de Saúde Pública, por Carlos Chagas, foi instituída a Inspetoria de Profilaxia da Lepra e Doenças Ve- 
néreas. As ações de controle de então priorizavam a construção de leprosários em todos os Estados endêmicos, o censo e o tratamento com o óleo de chaulmoogra. Conforme Carneiro (2002), foi neste período que Eduardo Rabello, ocupando o cargo de Inspetor Geral da Lepra, elaborou a primeira legislação brasileira da hanseníase e das doenças venéreas.

Foi também em 1920, com a criação da Inspetoria de Lepra e Doenças Venéreas (ILDV), primeiro órgão federal destinado à campanha contra a hanseníase, que houve uma sensibilização em todo o País quanto ao problema do Mal de Hansen, ocasião em que foram postas em prática as idéias promovidas por Emílio Ribas. Segundo Velloso e Andrade (2002), o isolamento dos pacientes teve seu início em 1927. Até 1934, ano da extinção do ILDV, foi feita a reforma dos serviços de saúde pública e foram fundados inúmeros hospitais-colônias e preventórios para conter a endemia. Ainda em 1934, foi criada a Diretoria dos Serviços Sanitários nos Estados, que teve, entre outras atribuições, cuidar do problema da hanseníase (Serviço Nacional de Lepra,1960).

Com a nova organização do Ministério da Educação e Saúde, em 1937, foi extinta a Diretoria dos Serviços Sanitários nos Estados, surgindo em seu lugar a Divisão de Saúde Pública, responsável pelo controle da hanseníase no território nacional. Em 1941, nova reforma na saúde pública cria o Serviço Nacional de Lepra, do Departamento Nacional de Saúde. A partir de então, o problema desta doença teve uma avaliação mais metódica e ampla, como há muito exigia a gravidade da endemia hansênica até então (Serviço Nacional de Lepra, 1960). Data desta época a criação dos dispensários, serviços ambulatoriais para investigação de casos novos e observação de casos suspeitos que seriam internados, caso fosse confirmado o diagnóstico.

Conforme Nogueira e cols. (1995, p.19), "o advento da sulfona no início da década de 40 , trouxe grande atento à comunidade científica, uma vez que se acreditava possivel o controle desta moléstia, foram realizadas grandes mudanças nas políticas de controle da doença e o tratamento através do isolamento compulsório foi abolido".

Atualmente, desde a década de 1950, o tratamento desta moléstia é feito em nível ambulatorial. Conforme Ferreira et. al. (1983) e Velloso e Andrade (2002), o internamento compulsório dos doentes de hanseníase foi abolido por lei, em todo o Brasil, no ano de 1954. Nogueira et. al. (1995) comentam sobre as mudanças nas políticas de controle da doença que efetivaram a extinção do isolamento compulsório, a partir da década de 1960.

Com o fim do isolamento compulsório, os doentes poderiam sair dos asilos, se assim o quisessem, e o tratamento poderia ser feito em centros de saúde. Porém, após décadas de segregação, muitos escolheram continuar nos "leprosários", simplesmente porque não tinham para onde voltar e nem como se sustentar na sociedade "sadia" com o dinheiro da aposentadoria que recebiam (Monteiro, 1987).

Surge então, a partir da década de 1960, modificação dos métodos profiláticos e nas políticas de controle da hanseníase, baseada na descentralização do atendimento e aumento da cobertura populacional, tratamento ambulatorial com sulfona, controle de comunicantes e educação sanitária (Velloso e Andrade, 2002). Em 1964, com o término da Campanha Nacional de Lepra, o nível federal transferiu a responsabilidade do Programa para os Estados.

A mudança do nome lepra para hanseníase, proposta por diversos autores na década de 1960, buscou afastar as fantasias e os preconceitos sobre a moléstia, além de favorecer a educação para a saúde (Rotberg, 1977). Todas as pessoas envolvidas com a doença devem divulgar, sempre que possível, os novos e atuais conceitos sobre a hanseníase: doença curável, de baixa contagiosidade e contra a qual a maioria da população tem defesas imunológicas naturais.

No ano de 1976, novas políticas para o controle da hanseníase determinam ações que visavam a educação em saúde, acompanhamento de comunicantes e aplicação de BCG, detecção de casos novos, tratamento dos doentes e prevenção e tratamento das incapacidades físicas que a doença pode causar (Velloso e Andrade, 2002).

No início da década de 1980, a Organização Mundial da Saúde passou a recomendar a poliquimioterapia (PQT), com esquema terapêutico apropriado a cada forma clínica da doença, para o controle e cura da hanseníase. Além dos medicamentos da PQT, medidas como diagnóstico precoce, vigilância dos comunicantes, prevenção e tratamento das incapacidades físicas e educação para a saúde fazem parte das 
políticas atuais. Este é o esquema vigente em todo o território nacional na atualidade, sendo que no Rio Grande do Sul, a PQT foi implementada a partir de julho de 1992 (Gomes et al., 1998; Peres, 1997).

$\mathrm{Na}$ atualidade, conforme dados do Ministério da Saúde (Brasil, 2004), a prevalência da hanseníase no Brasil é de 3,88 doentes para cada dez mil habitantes, sendo que a OMS considera eliminada como problema de saúde pública quando a taxa de prevalência é menor do que um doente para cada dez mil habitantes. A hanseníase tem alta prevalência nos Estados do Acre, Amapá, Amazonas, Maranhão, Mato Grosso, Pará, Piauí, Rondônia e Roraima. Santa Catarina e Rio Grande do Sul já eliminaram a hanseníase e São Paulo, Rio Grande do Norte e Distrito Federal estão próximos de atingir a eliminação. O Rio Grande do Sul atingiu a meta de eliminação em 1995, e em 2002 a taxa de prevalência foi de 0,22 .

\section{Considerações Finais}

A importância desta evolução histórica, discorrida desde os primórdios da humanidade até os dias atuais, encontra-se no fato de possibilitar a divulgação de conhecimentos acerca da hanseníase e dos fatores contribuintes para o seu surgimento e controle, contribuindo, desta maneira, com a epidemiologia. Permite, ainda, a compreensão de diversas atitudes e sentimentos dos doentes de hanseníase que chegam para atendimento pela equipe de saúde fragilizados, deprimidos e até mesmo revoltados, tendo em vista as discriminações e preconceitos vivenciados ao longo dos tempos e, também, na atualidade. A partir desta compreensão, é possível prestar tratamento integral ao hanseniano, tanto na esfera biológica, quanto na psicossocial.

\section{Referências}

ARAÚJO, H. C. S. Contribuição à epidemiologia e prophylaxia da lepra no Norte do Brasil. Memórias do Instituto Oswaldo Cruz, Rio de Janeiro, v. 27, n. 3 , p. 165, 1933.

AVELLEIRA, J. C. R.; NERY, J. A. O tratamento da hanseníase. Rio Dermatológico, Rio de Janeiro, v. 2, n. 3 , p. 2-3, 1998.
BASSEWITZ, E. V. A questão da lepra no Rio Grande do Sul. Arquivos Riograndenses de Medicina, Porto Alegre, v. 6, n. 1, p. 10-12, 1927.

BÍBLIA SAGRADA. 82. ed. São Paulo: Editora Ave Maria, 1992.

BRASIL. Ministério da Saúde. Controle da hanseníase: uma proposta de integração ensino-serviço. Rio de Janeiro: DNDS/NUTES, 1989.

BRASIL. Ministério da Saúde. Manual de prevenção de incapacidades. Brasília: Área Técnica de Dermatologia Sanitária, 2001.

BRASIL. Ministério da Saúde. Saúde Brasil, Brasília, Edição n. 95, abril 2004.

CALMON, P. História da civilização brasileira. Rio de Janeiro: [s.n.], 1940. p.119.

CAMELLO, R. S. Levantamento de causas do abandono de tratamento de hanseníase no município de Porto Alegre. Porto Alegre, 2002. Monografia (Curso de especialização em Epidemiologia com ênfase em vigilância em Saúde) - ESP/Universidade Federal de Pelotas.

CARNEIRO, G. História da dermatologia no Brasil: dados sobre a especialidade e a sociedade científica; edição comemorativa dos 90 anos da fundação da Sociedade Brasileira de Dermatologia. Rio de Janeiro: Sociedade Brasileira de Dermatologia, 2002.

CARVALHO, A.S. História da lepra em Portugal. Porto: [s.n.], 1932.

CUNHA, A. Z. S. Hanseníase: a história de um problema de saúde pública. Santa Cruz do Sul, 1997. Dissertação (Mestrado em Desenvolvimento Regional) - Universidade de Santa Cruz do Sul.

DANIELSEN, D. C.; BOECK, W. Traité de la Spédalskdhed. Paris: Chez. J.B. Bailliére, 1848.

EIDT, L. M. O mundo da vida do ser hanseniano: sentimentos e vivências. Porto Alegre, 200o. Dissertação (Mestrado) - Faculdade de Educação da PUCRS.

FAILLACE, M. Do conceito da profilaxia da lepra. Monografia. Porto Alegre, 1933.

FERREIRA, J. et. al. Controle da hanseníase num sistema integrado de saúde. Boletin de la Oficina Sanitária Panamericana, Washington, v. 95, n. 6, p. 507-515, 1983. 
FOSS, N. T. Hanseníase: aspectos clínicos, imunológicos e terapêuticos. Anais Brasileiros de Dermatologia, Rio de Janeiro, v. 74, n. 2, p. 113-19, 1999.

GOMES, A. C. B. O processo de Armauer Hansen. Jornal do Conselho Regional de Medicina do Rio Grande do Sul, p.13, fev. 2000 .

GOMES, A. C. B. et al. Hanseníase no Rio Grande do Sul: situação atual. Boletim Trimestral de Dermatologia da Sociedade Brasileira de Dermatologia Secção RS, v. 8, n. 3o, p. 5, 1998.

GUEDES, T. C. Considerações sobre a lepra e sua prophylaxia. Tese. Bahia, 1930.

JOHNSTON, P. BC's “Island of death" marked a sad chapter in Canada's medical history. Canadian Medical Association Journal, Toronto, v.152, n. 6, p. 951-952, 1995 .

JOPLING, W. H.; McDOUGALL, A. C. Manual de hanseníase. 4a. ed. Rio de Janeiro: Livraria Atheneu Editora, 1991.

JORNAL DO MORHAN. Órgão oficial de divulgação do movimento de reintegração das pessoas atingidas pela Hanseníase. n. 35, jul/ago. 2000.

MAGALHÃES, J. L. A morphéa no Brasil. Rio de Janeiro: [s.n.], 1882.

MATTA, A. Escorço histórico da lepra no Estado do Amazonas. Ciência Médica, Rio de Janeiro, v. 7, n. 4, p.181, 1924.

MAURANO, F. História da lepra em São Paulo. São Paulo: [s.n.], 1939.

MAURANO, F. Tratado de leprologia. Rio de Janeiro: Serviço Nacional de Lepra, 1944. V. 1 - História da lepra no Brasil e sua distribuição geográfica.

MONTEIRO, Y. N. Hanseníase: história e poder no Estado de São Paulo. Hansenologia Internationalis, São Paulo, v. 12, n.1, p.1-7, 1987.

NOGUEIRA, W. et. al. Perspectivas da eliminação da Hanseníase. Hansenologia Internationalis, São Paulo, v. 20, n. 1, p. 19-28, 1995.

OPROMOLLA, D. V. A. Noções de hansenologia. Bauru: Centro de Estudos Dr. Reynaldo Quagliato, 1981.

OPROMOLLA, D.V. A. Noções de hansenologia. Bauru: Centro de Estudos Dr. Reynaldo Quagliato, 2000.
ORGANIZACIÓN PANAMERICANA DE LA SALUD/ ORGANIZACION MUNDIAL DE LA SALUD (OPS/ OMS). Lepra al dia: situacion de la eliminación de la lepra en algunos paises de la America Latina. Boletin Eliminación de la Lepra de las Ameritas, n. 9, nov. 2001.

PERES, M. P. Experiência com poliquimioterapia em hanseníase no Estado do Rio Grande do Sul. Boletim Trimestral de Dermatologia da Sociedade Brasileira de Dermatologia - Secção RS, v. 7, n. 25, p. 6-7, 1997.

PINHEIRO, M. F. B. Irmandade do S.S. da Freguezia da N.S. da Candelária e suas repartições, coro, caridade e Hospital dos Lázaros. Rio de Janeiro: [s.n.], 1894.

PINTO, P.G.H.R. O estigma do pecado: a lepra durante a Idade Média. PHYSIS - Revista de Saúde Coleti$v a$, Rio de Janeiro, v. 5, n. 1, p. 131-144, 1995.

RODRIGUES, A.L. et al. Guia para a utilização de medicamentos e imunobiológicos na área de hanseníase. Brasília: Ministério da Saúde, 2000.

ROTBERG, A. A antiga, permanente e poderosa antieducação com a palavra "lepra" e sua frustração através de nova terminologia. Doença Hanseníase, São Paulo, v. 1, n. 1, p. 26-33, 1977.

SANTIAGO, P. E. A lepra em Santa Catarina. Revista Combate à Lepra, Rio de Janeiro, v. 6, n. 4, 1941.

SERVIÇO NACIONAL DE LEPRA. Manual de leprologia. Rio de Janeiro: Departamento Nacional de Saúde, 1960.

SKINSNES, O. Imunopathology os leprosy: the century in review. International Journal Leprosy, Washington, v. 42, p. 329-36o, 1973.

SOUZA ARAÚJO, H. C. Memórias do Instituto Oswaldo Cruz. Rio de Janeiro: Departamento de Imprensa Nacional, 1918.

SOUZA ARAÚJO, H. C. História da lepra no Brasil. Rio de Janeiro: Imprensa Nacional, 1946.

TALHARI, S; NEVES, R. G. Hanseníase. $3^{\mathrm{a}}$.ed. Manaus: Gráfica Tropical, 1997.

TERRA, F. Esboço histórico da lepra no Brasil. Anais brasileiros de Dermatologia, Rio de Janeiro, v. 2, n. 1, p.3-4, 1926. 
VEIGA, P. J. X. Ephemérides mineiras (1664-1897). Ouro Preto: [s.n.], 1897.

VELLOSO, A. P.; ANDRADE, V. Hanseníase: curar para eliminar. Porto Alegre: Edição das autoras, 2002.
VIRMOND, M. A hanseníase como doença de baixa prevalência. Hansenologia Internationalis, São Paulo, v. 20, n.2, p. 27-35, 1995.

Recebido em: 27/01/2004

Aprovado em: 01/06/2004

88 Saúde e Sociedade v.13, n.2, p.76-88, maio-ago 2004 